\title{
CRITERIA FOR PEER REVIEWING THE ORIGINAL ARTICLES SUBMITTED T O A BIOMEDICAL JOURNAL: INTELLECTUAL HONESTY IS THE BEST POLICY
}

Paudel B H

\section{ABSTRACT}

Peer review - a process of assessing the quality of manuscripts submitted to a journal - is an established norm in biomedical publications. It is viewed as an extension of scientific process. The peer-reviewed research articles are considered trustworthy because they are believed to be unbiased and independent. The process of reviewing is a privilege and prestige. It is highly responsible, intellectually honest, and difficult job. Being expert in certain area of biomedical science is a prerequisite for reviewers. Young peer reviewers trained in epidemiology or statistics produce high-quality review. The International Congresses on Peer Review in Biomedical Publication have shown many unresolved issues related to preparation or handling of manuscripts by a journal. Therefore, it is vital to identify authentic peer reviewers to ensure quality publication, thus, a set of peer review criteria is proposed for peer reviewing original articles. It is useful in quantifying (scoring) the manuscript quality. The proposed scoring system yields three categories of manuscripts: the first category is considered acceptable for publication after minor modification by editorial board and/or reviewers, the second - requires rewriting and resubmission, and the third - rejected. These criteria are preliminary guidelines, and require timely review. They are expected to sensitise peer reviewers, editors, contributors, and readers to move towards greater honesty and responsibility while working with manuscripts. In summary, if the criteria are used they will facilitate editorial management of manuscripts, render more justice to authors and biomedical science, and improve publication quality.

\section{Key Words: Biomedical publication, peer review, peer review criteria, scoring of manuscripts, categories of manuscripts, journal of Nepal Medical Association.}

Biomedical Research

Biomedical science progresses as application of its research outcome advances. Thus, research in biomedical fields is an obligation for moving medical science and public health ahead. The research yields facts and they are documented. Documentation of facts has been one of the biggest achievements in modern world, and it has made an immense effect on research on health and medical sectors worldwide. There has been extensive and intensive research in the biomedical field in the last century, especially in its second half, and documentation of research findings has become a standard and regular practice.
Documentation of research findings or facts, printed or demonstrated in authentic periodicals and electronic media, is known as publication. The biomedical research publication, generally, contains a statement of research question, its objective, pre-designed method, observation, and an account of interpretation of new findings. The new findings are weighed and contrasted against already known (published) facts and presented under the theme of discussion. ${ }^{1}$ While discussing, a good researcher does not hide the limitations of his/her study rather s/he prefers to share them, and gives future perspectives too. Therefore, a research is also called a disciplined enquiry of research question(s). The entire presentation of the

Address for correspondence : Dr. Bishnu Hari Paudel

B. P. Koirala Institute of Health Sciences, Dharan, Nepal.

Email: bhpaudel2002@yahoo.com 
publication is expected to be scientific, concise, simple, selfexplanatory, and of course, intellectually honest.

There are probably thousands of biomedical periodicals (journals) published worldwide at certain intervals. The journal of the Nepal Medical Association (JNMA) is one of such periodicals, which has about four decades of history of scientific publication. The scientific publications in the journal, nowadays, appear after scrutinizing the manuscripts by peer reviewers. There are few more such journals published in Nepal.

\section{WHAT IS PEER REVIEW?}

For publication of a scientific work in a journal, authors submit manuscript of their research work in a printed form and/or in its electronic version. Before the research work is printed as a publication, the manuscript undergoes an editorial processing. The journal editors identify specific peer-scientists to critically evaluate the publication potential of the submitted manuscripts. A peer reviewer is the expert in certain area of biomedical sciences, and the peer review is the evaluation of importance and quality of original research manuscripts. Peer review is an intrinsic part of all scholarly work, including the scientific process. Peer reviewers are the experts who are not a part of the editorial staff. Ideally, the review is unbiased, independent, and critical assessment of the manuscript. Peer review can therefore be viewed as an important extension of the scientific process. Although its actual value has been little studied, and is widely debated, peer review helps editors decide which manuscripts are suitable for their journals, and helps authors and editors in their efforts to improve the quality of research reporting. A journal that has undergone such reviewing is one that submits most of its published research articles for outside review before their publication. The number and the type of the manuscripts sent for review, the number of reviewers, the reviewing procedures, and the use made of the reviewers' opinions may vary according to journal's publication policy.

Peer-reviewed research articles are considered highly trustworthy biomedical research because they have undergone scrutiny by experts who are knowledgeable in the topic. The peer review of original articles, before they are published, has been widely accepted practice and it is a norm in biomedical publications. In the interests of transparency, each journal should publicly disclose its policies in its instructions to authors. ${ }^{2}$ The biomedical journals worldwide follow certain guidelines for reviewers. It makes the job of the reviewer more objective. Simultaneously, the contributing authors would find unbiased judgement on their research work. The job of editors would also be facilitated and they may keep a record of performance of individual reviewer so that they can refer to them for subsequent review requests.

The process of reviewing is a privilege and prestige for the reviewers. ${ }^{3}$ It should also be recognised that the task of reviewing a scientific research work is a great responsibility. It demands honesty, especially the intellectual honesty, on the part of reviewers. In other words, the reviewer should be clear enough that if $s /$ he is not an expert in the field on which a manuscript has been asked to review, s/he should honestly reject reviewing the manuscript or a part of it. Then s/he should convey to the editorial board that $\mathrm{s} / \mathrm{he}$ is not in a position to review the given paper or a part of it.

\section{AIMS OF THIS ARTICLE}

The aim of this article is to propose a set of peer review criteria and highlight its usefulness in the process of quantifying the peer review. It is also aimed to sensitise all the concerned scientists and doctors i.e., reviewers, editors, authors and critical readers of national and international biomedical journals.

\section{RATIONALE OF DISCUSSING PEER REVIEW IN THE NATIONAL CONTEXT}

The practice of peer review has been adopted by the journal of Nepal Medical Association (JNMA) because, I believe, the editorial board of the journal, and quality-concerned medical scientists including this author, have understood that there is a pressing need to further improve the publication quality of the journal. The publication quality has also been a matter of concern for the entire NMA family and its active members. The efforts are, albeit slow, moving on positively to make the journal internationally recognisable. Therefore, this paper is an attempt to highlight some major issues to be dealt seriously so as to minimise the (assumed) potential errors of peerreviewing and facilitate the decision making process of editorial board before an original article appears in the JNMA and other biomedical journals published in Nepal.

Unfortunately, we do not have concrete data regarding the performance of peer reviewers and publication quality of the national biomedical journals, especially the JNMA; therefore, this article is primarily based on supposition and occasional remarks done by editors, reviewers, authors, and readers of the JNMA. However, on the basis of reviewing experience of about a dozen of manuscripts submitted to the JNMA in recent past, and review of research grant projects of BP Koirala Institute of Health Sciences; this author is encouraged to speculate that most of the manuscripts submitted to the JNMA required transformational changes before they were acceptable 
for publication. This assumption might be true for many biomedical journals published worldwide. Thus, minimising the transformational editing and imparting justice to the authors and the health/biomedical science are essential for the journal. An investigation is required to answer the question of imparting justice to science and the authors. However, there is perceivable evidence on JNMA performance and sufficient support from international literature to justify discussion on the topic of peer review. Furthermore, the international literature on importance of peer review is full of concrete evidences to convince this author to raise the issue of quality peer review. Thus, this author's speculation has genuine ground. Peer review of many submissions including the JNMA submissions bear special significance because, as international literature says, peer reviewed research articles are, and should be, highly credible because they have undergone scrutiny by speciality experts.

\section{SOURCE OF THIS ARTICLE}

This article is the outcome of review of relevant research publications pertaining to peer review and related issues presented in the First to Fourth (1989, 1993, 1997, and 2001) International Congresses on Peer Review in Biomedical Publication (ICPRBP). A special emphasis has been given to the papers presented in the Third ICPRBP (held in September 1997 in Prague, Czech Republic), which were subsequently published in the Journal of American Medical Association (JAMA). The entire issue of the journal (1998, Vol. 280, issue 3) deals with the papers on peer reviewing, editorial policy, and publication practices regarding authorship, gender biases, assessment of reviewers' performance etc. It is worth noting here that the JAMA regularly monitors editorial performance, which includes review time, editorial decisions, and publication ${ }^{4}$ without interfering the review process or editorial decision. Going through the entire issue of the journal this author found that it is extremely useful and would be of great relevance for editors, reviewers and even for the readers in further improving the quality of national biomedical publications.

\section{BRIEF ACCOUNT OF WHAT THE WORLD LITERATURE SAY ABOUT PEER REVIEW}

The Second ICPRBP discussed primarily about the management of manuscript by editors. In the Third ICPRBP various aspects of quality of publication were discussed. It was observed that reviews often seemed inconsistent, unreliable, and even incompetent; and the comment of reviewers may be hasty and superficial. ${ }^{5}$ However, good reviewers, if provided with relevant material along with the abstract and full-length paper, find helpful for peer reviewing. Even masking the review process has given conflicting reports on quality of review and it has added new biases, for example, delay in publication of articles on passive smoking studies with non-significant results as compared to those with significant results. ${ }^{6}$ Similarly, Callaham et al., have reported that analysis of abstracts submitted to a scientific meeting showed that the abstracts with positive-results were accepted more for presentation and publication. ${ }^{7}$

It has been found that there are fewer women in editorial position in epidemiology journals in the USA. Its cause is still not known but it sufficiently indicates possibility of selection bias in appointing editors in such positions. ${ }^{8}$ The US reviewers are found to favour the papers submitted by the US citizens than the non-US, and even the non-US reviewers were inclined to behave like US reviewers. ${ }^{9}$ It may be called citizen bias. It is not surprising that reviewing a review article has been a very responsible and difficult task and its review depends on reviewer's discipline and nationality. ${ }^{10}$ Thus, the world literature contains existence of bias in biomedical publication and its system. It is an unsafe practice in science, which might lead society in wrong direction. Therefore, continuous efforts are going on to minimise bias in biomedical publications by bringing out the flaws detected in literature.

During the Fourth ICPRBP some more exploration on the issue was done. An American study assessed journal quality indicators (peer review status, impact factor, citation rate, acceptance rate, circulation, MEDLINE indexing, and Brandon's Library List indexing) as valid predictors of research article methodological quality of randomised and nonrandomised controlled trials of 30 general medical journals. All the journals included in the study were peer reviewed and indexed in MEDLINE. Multivariate analysis showed that citation rate alone was the most reliable predictor of journal article quality. The study concluded that high citation rates, impact factors and circulation rates, low manuscript acceptance rates, and indexing on Brandon's list appear to be predictive of higher methodological quality scores for articles published in the journals. ${ }^{11}$

The role of reviewers is difficult in the sense that they have to work as an advocate of a journal (role of editor) and as an advocate of authors (role of authors). While working as journal advocate if s/he rejects a manuscript, it makes authors pessimistic about chance of subsequent publication by them. ${ }^{12}$ Thus, considering the current status of manuscript submission to the JNMA and many other national journals publishe in Nepal, such negative impact resulting from rejecting manuscript should be minimised by providing valuable suggestions, if possible with evidence from available literature, to the author(s) in a decent language so that authors are supported and not discouraged. 
There has been poor agreement between abstract and body of full paper in international literature, ${ }^{13}$ and this author is tempted to speculate that the issue might be extremely serious in the biomedical publications in Nepal. Using Consolidated Standards of Reporting Trials (CONSORT) descriptor criteria have been considered a gold standard in reporting randomised controlled trials. It has been found that there is no difference in text reporting associated structured abstract using CONSORT descriptor criteria to evaluate reporting quality and without using CONSORT descriptor criteria. ${ }^{14}$ The study was focused on two different American Ophthalmology journals during the first half of 1990s. Furthermore, even the leading biomedical journals of the world (BMJ, JAMA, The Lancet etc) did not adequately follow the CONSORT recommendations. ${ }^{15}$ Therefore, it is presumed that there is a need to investigate the adherence of authors to prescribed format of biomedical publications. An indication towards non-adherence of authors to prescribed format of the JNMA submissions may be found in various areas and especially in the referencing system of the JNMA. In fact, this author, after reviewing about a dozen of manuscripts recently, did not find even a single author who completely adhered to the Vancouver style of stating references. It is worth mentioning here that the Vancouver System of referencing has already been upgraded and is called Uniform Requirements for Manuscripts Submitted to Biomedical Journals: Writing and Editing for Biomedical Publication.

\section{EFFECT OF MASKING ON PEER REVIEW QUALITY}

Masking author identity is not associated with success of reviewing but for reviewers with less research or reviewing experience it might increase the success. ${ }^{16}$ Some other studies on blinding and unmasking authors identity to reviewers or making reviewers to sign their review reports or masking reviewers to authors have failed to show significant effect on the quality of peer review. ${ }^{17,18,19,20}$ Even a written feedback by editors to peer reviewers has not improved the quality of subsequent reviews. ${ }^{21}$ Irrespective of size (big or small) of the journal, reviewers' recommendations have been found to be similar influence on editorial decision. ${ }^{22}$ A study has shown that about $50 \%$ peer-reviewers want disclosing their identity in the article if their institute /organization recognizes their contribution to the article they reviewed. About two third of them did not favour the disclosing because they perceived that their institute does not recognize their contribution. ${ }^{23}$ Nevertheless, the peer review is being practiced and is considered gold standard before manuscripts are published in biomedical scientific periodicals ${ }^{24}$ and thus, it is necessary for the progress of research reporting in biomedical sciences.

The above-mentioned evidence shows that reviewing is an extremely difficult task, even in the countries where research culture is well established, in doing justice to the authors and science. Now, the editorial board along with concerned members of the NMA and the authorities of other biomedical journal of Nepal would agree with the notion that the majority of national biomedical journals have a Herculean task ahead in making their publication international along with imparting justice to their scientific contributors and national biomedical science. We should be optimistic that with the improvement in peer review and submission quality, the publication quality will definitely go up. For example, some improvement in use of statistical tools has been found in Chinese biomedical publications possibly owing to input from statistical reviewer. ${ }^{25}$ However, peer reviewers are also found to do mistakes making unfounded statistical criticism in difficult areas such as sample size and multiple comparisons. This is usually from subject matter reviewers with limited statistical knowledge. ${ }^{26}$ Therefore, it may be recommended that the JNMA editorial board identify genuine peer reviewers to ensure quality in its publications. Similarly, other national biomedical journals, since their experience is in early childhood, may need this approach.

\section{WHAT ARE THE ATTRIBUTES OF A GOOD REVIEWER?}

The assessment of cognitive process that reviewers use while evaluating a manuscript has been considered time consuming, difficult and expensive. ${ }^{5}$ The reviewers trained in epidemiology or statistics are known to produce high-quality peer review and the review quality improves if they increase the time for reviewing up to 3 hours for a manuscript. Spending time beyond 3 hours does not increase the review quality. ${ }^{27}$ This time may be more for us who learn English as a non-native language. They find it helpful if they are provided with relevant material along with the abstract and full-length paper.

It is important to note that the reviewers require some training for quality peer reviewing. Not only the reviewers, even the editors would also like to have training regarding their role or job of review process on time because ideal reviewers or editors are found to be of young age, i.e., below 60 years. ${ }^{27}$ In addition, it has been believed that editors and reviewers are extremely busy people.

Being an expert is obviously the prerequisite for a reviewer. However, there are some other important qualities, which help the reviewer to be a fair critic. To name few, these qualities are: having critical mind, broad-based knowledge of basic medical and clinical sciences including natural sciences (physics, mathematics, chemistry etc.). Philosophical understanding, in terms of dialectical thinking (both inductive and deductive), helps to put evidences in logical sequence. 
Simultaneously, strong foundation in various aspects of biology such as biology of lower animals, vertebrates and comparative biology, and sociology is an extra benefit.

\section{BIOMEDICAL PUBLICATION IN FUTURE}

Presenting as the opening address of the Third ICPRBP in Prague (1997) Dr. Rennie, the deputy editor (West) of JAMA, predicted that in the future authorship will be abolished in favour of contribution and the work done by the contributors will be listed for the readers, peer review will become open, and anonymous review will be obsolete, scientists will take full responsibility for aftercare of their papers, and editors enable and encourage readers to assume the responsibility of reviewers. ${ }^{28}$

\section{FOR THE EDITORS AND JOURNAL AUTHORITIES}

Based on the review of international literature an attempt has been made in this article to suggest a set of criteria (vide infra Table) for the process of peer reviewing. These criteria are based on international literature and have tremendous potential for immediate use. It is expected that these criteria will be followed in the process of management of manuscripts submitted to the biomedical journals. This author believes that these criteria have been made suitable for current standard of the journal and would go on improving dynamically as editorial policy, readers' concern etc. go on changing with time, and a strong scientific culture establishes in the country. With the improvement in publication quality and habit of using published reports, we can hope some advancement in national biomedical sciences.

It is worth mentioning here some other issues that may be related to the job of the journal editorial boards. It appears that time has come for the national journals to deal with publication disputes, which might be expected in near future. Thus, the authorities of a journal may constitute an independent body, consisting of its intellectually honest members, to look into the matter pertaining to the complaints of manuscript contributors, authorship, and other related issues. ${ }^{29}$ Regarding the authorship of a paper, the departments/sections from where the paper originates should establish their detailed, written guidelines on authorship practices. ${ }^{30}$ If editors wish (may be they need!) to evaluate their reviewers, this author believes that our reviewers will not object this idea. It can be done with minimal additional work on the part editorial board. The editors need to develop a simple rating scale to monitor reviewer quality. Such a rating system could be used for awarding the best reviewers during regular conferences/ meetings to encourage them. Although making reviewers to sign their review reports has not been found to improve quality of peer review, ${ }^{18}$ the editors of a journal may decide whether such a measure would be useful for them. Nevertheless, in the initial stage of journal quality development, a commitment by reviewer such as "I have reviewed the research work or part of it with full knowledge of the content and I have been intellectually honest throughout my review process, and my comments or suggested modifications are unbiased and critical" may be useful to obtain from the reviewers. Such a measure might make the peer reviewers more conscious and responsible. This sort of regulation may be practiced for initial few years until a journal's editorial board identifies sufficient number of qualified peer reviewers.

\section{FOR REVIEWERS, EDITORS, AND READERS OF A BIOMEDICAL JOURNAL}

It is expected that the suggested set of criteria (vide infra Table) for reviewers will facilitate their peer-review process so that publication quality is taken care and justice to authors/ contributors is imparted. Majority of the criteria are based on literature and some other points of the criteria (taxonomy list) are incorporated and adjusted by this author arbitrarily judging the present status of JNMA performance. However, the proposed scoring system is entirely this author's creation, it is unlikely that the readers will encounter such a scoring system for peer reviewing in national or international literature.

This author believes that these criteria would go on changing to meet national demand and the future international guidelines. Currently, adhering to the proposed guideline would make us objective and this objectivity should primarily help editorial decision-making on the acceptability of original article for publication. In turn, the journal will definitely move faster towards internationalisation. Implementation of the criteria, and timely advancement would prevent us from danger of deinternationalisation of our would-be-international journal. ${ }^{31}$ The proposed manuscript scoring criteria may be of some use for scoring the manuscript submitted to other national (even international) biomedical journals.

\section{USING THE CRITERIA}

These criteria are only a rough and preliminary guideline and they are subject to modification depending on the editorial policy. These criteria are most useful in reviewing original articles; they may be of some use while reviewing review articles, research projects, case reports, letters to editors etc.

The maximum possible score that a manuscript can secure is 42 and the minimum is minus 21. Negative marking is required if the items 3 and 6 are violated. Based on the score secured by a manuscript after peer review, its quality and publication 
Table I : The Criteria for reviewing of paper submitted to a biomedical journal (Reviewer's guide)*

\begin{tabular}{|c|c|c|c|c|c|}
\hline \multirow{2}{*}{$\begin{array}{l}\mathbf{S} \\
\text { No } \\
1\end{array}$} & \multirow{2}{*}{$\begin{array}{l}\text { Taxonomy } \\
\text { Adequacy of scientific quality } \\
\text { of research (appropriateness of } \\
\text { method and its clarity, } \\
\text { robustness of data to reach the } \\
\text { conclusion, fulfilment of } \\
\text { objective, generalizability) }\end{array}$} & \multicolumn{4}{|c|}{ Score } \\
\hline & & $\begin{array}{c}4 \\
\text { Adequate }\end{array}$ & $\begin{array}{l}3 \\
\text { Requires some } \\
\text { addition or clarity }\end{array}$ & $\begin{array}{l}2 \\
\text { Requires substantial } \\
\text { addition or clarity }\end{array}$ & $\begin{array}{c}1 \\
\text { Inadequate }\end{array}$ \\
\hline 2. & $\begin{array}{l}\text { Significance of research finding } \\
\text { (scientific value, exploration } \\
\text { mechanism of health/biomedical } \\
\text { phenomenon, potentiality of use: } \\
\text { public health, national/ } \\
\text { international) }\end{array}$ & $\begin{array}{c}4 \\
\text { High (immediate } \\
\text { use, high } \\
\text { scientific value, } \\
\text { national/global } \\
\text { value) }\end{array}$ & \begin{tabular}{|c|}
3 \\
Medium (Regional \\
significance, likely \\
use in near future \\
or regionally)
\end{tabular} & $\begin{array}{c}2 \\
\text { Low (Use in a small } \\
\text { population group, } \\
\text { use likely after } \\
\text { many years) }\end{array}$ & $\begin{array}{c}1 \\
\text { Extremely low } \\
\text { (Poor public health } \\
\text { / scientific } \\
\text { importance, use less } \\
\text { likely) }\end{array}$ \\
\hline 3. & $\begin{array}{l}\text { Originality of research work } \\
\text { (newness of finding, duplication } \\
\text { of study, extension of previous } \\
\text { work, intentional copying or } \\
\text { plagiarism) }\end{array}$ & $\begin{array}{c}4 \\
\text { Original and new }\end{array}$ & $\begin{array}{c}3 \\
\text { Deliberate } \\
\text { duplication to } \\
\text { confirm previous } \\
\text { finding or } \\
\text { advanced } \\
\text { extension of } \\
\text { previous work }\end{array}$ & $\begin{array}{c}2 \\
\text { Small part of a } \\
\text { previous work }\end{array}$ & $\begin{array}{c}\text { Minus } 15 \\
\text { Copy or plagiarism }\end{array}$ \\
\hline 4. & $\begin{array}{l}\text { Presentation quality (logical } \\
\text { sequence of text, paragraphing; } \\
\text { tables and figures, and their self- } \\
\text { explanatory nature) }\end{array}$ & $\begin{array}{c}3 \\
\text { Very good }\end{array}$ & $\begin{array}{c}2 \\
\text { Good }\end{array}$ & $\begin{array}{c}1 \\
\text { Poor }\end{array}$ & $\begin{array}{c}0 \\
\text { Extremely poor }\end{array}$ \\
\hline 5. & $\begin{array}{l}\text { Language adequacy } \\
\text { (correctness of English structure, } \\
\text { simplicity, style) }\end{array}$ & $\begin{array}{c}3 \\
\text { Adequate }\end{array}$ & $\begin{array}{c}2 \\
\begin{array}{c}\text { Requires some } \\
\text { editing }\end{array}\end{array}$ & $\begin{array}{c}1 \\
\text { Requires substantial } \\
\text { improvement }\end{array}$ & $\begin{array}{c}0 \\
\text { Inadequate }\end{array}$ \\
\hline 6. & $\begin{array}{l}\text { Ethical issue (statement of } \\
\text { following standard ethical } \\
\text { guidelines: national - NHRC } \\
\text { and/or international - Helsinki } \\
\text { declarations, research violation) }\end{array}$ & $\begin{array}{c}2 \\
\text { Statement } \\
\text { confirms absence } \\
\text { of violation }\end{array}$ & $\begin{array}{c}1 \\
\text { Unclear statement }\end{array}$ & $\begin{array}{c}0 \\
\text { No statement }\end{array}$ & $\begin{array}{l}\text { Minus } 8 \\
\text { Violated }\end{array}$ \\
\hline 7. & $\begin{array}{l}\text { Statement of strength and } \\
\text { weakness of the work }\end{array}$ & $\begin{array}{c}3 \\
\text { Both well stated }\end{array}$ & $\begin{array}{l}2 \\
\begin{array}{l}\text { Requires some } \\
\text { addition }\end{array} \\
\end{array}$ & $\begin{array}{c}1 \\
\text { Requires substantial } \\
\text { addition }\end{array}$ & $\begin{array}{c}0 \\
\text { No statement }\end{array}$ \\
\hline 8. & $\begin{array}{l}\text { Type of research: randomised } \\
\text { controlled trial to case reports }(5 \\
-1)\end{array}$ & $\begin{array}{c}5 \\
\text { Randomised } \\
\text { controlled trial }\end{array}$ & $\begin{array}{c}4.5,4,3.5 \\
\text { Non-randomised } \\
\text { trial or multiple } \\
\text { time series, cohort, } \\
\text { case control }\end{array}$ & $\begin{array}{c}3,2.5 \\
\text { Case series, cross } \\
\text { sectional }\end{array}$ & $\begin{array}{c}1 \\
\text { Case report }\end{array}$ \\
\hline 9. & $\begin{array}{l}\text { Agreement between abstract and } \\
\text { body of full length article }\end{array}$ & $\begin{array}{c}3 \\
\text { Very good }\end{array}$ & $\begin{array}{c}2 \\
\text { Good }\end{array}$ & $\begin{array}{c}1 \\
\text { Poor }\end{array}$ & $\begin{array}{c}0 \\
\text { Extremely poor }\end{array}$ \\
\hline 10. & $\begin{array}{l}\text { Adequacy of literature review } \\
\text { to justify the rationale and } \\
\text { objectives / hypothesis of the } \\
\text { study }\end{array}$ & $\begin{array}{l}3 \\
\text { Adequately } \\
\text { justified }\end{array}$ & $\begin{array}{l}2 \\
\text { Justification } \\
\text { requires some } \\
\text { addition }\end{array}$ & $\begin{array}{l}1 \\
\text { Requires substantial } \\
\text { addition }\end{array}$ & $\begin{array}{l}\text { No justification of } \\
\text { the study }\end{array}$ \\
\hline 11. & $\begin{array}{l}\text { Adequacy of statistical tool } \\
\text { used (appropriateness of } \\
\text { statistical tool: inferential to } \\
\text { support hypothesis, descriptive } \\
\text { etc) }\end{array}$ & $\begin{array}{c}3 \\
\text { Adequate }\end{array}$ & $\begin{array}{l}\text { 2 } \\
\text { Some more } \\
\text { statistics is } \\
\text { required to draw } \\
\text { inference }\end{array}$ & $\begin{array}{l}\text { Substantial statistics } \\
\text { is required to draw } \\
\text { inference }\end{array}$ & $\begin{array}{c}\text { Up to Minus } 2 \\
\text { Misuse or wrong } \\
\text { use statistical tool } \\
\text { or no data presented }\end{array}$ \\
\hline 12. & $\begin{array}{l}\text { Overall rating of the research } \\
\text { work } \\
\text { Total Score }\end{array}$ & $\begin{array}{c}5 \\
\text { Very good } \\
\text { Maximum }=\mathbf{4 2}\end{array}$ & $\begin{array}{c}4 \\
\text { Good } \\
\text { 30.5 to } 29.5\end{array}$ & $\begin{array}{c}3 \\
\text { Borderline } \\
\mathbf{1 8} \text { to } \mathbf{1 7 . 5}\end{array}$ & $\begin{array}{c}1 \\
\text { Poor } \\
\text { Minimum }=\mathbf{- 2 1}\end{array}$ \\
\hline
\end{tabular}

potentiality may be categorised as the scoring: 1) equal or more than 28.5 may be accepted for publication after minor changes by reviewer(s) and/or editorial board, 2) between 14.5-28 is acceptable only after clarifying/incorporating all the comments and suggestions of reviewers and/or editorial board, and 3) between below 14 is rejected. In the case of first category, publication of the article primarily depends on editorial board and/or reviewers' input whereas in the second category, the 
authors are responsible for further revision and resubmission of their manuscript. Based on the score obtained by a manuscript, further management of the editorial board would be either accept the manuscript for publication or send it back to the author(s) for revision or reject it. In controversial situations, the board may get opinion of two or more peer reviewers, club their scores, and act accordingly.

The above criteria have been proposed for the sake of objectivity in assessing a manuscript but one should also keep in mind that being too mathematical may not always be fruitful. Some of the items of the criteria may not be applicable to the articles of policy matters or census type of studies. In such cases, review may be done using the same taxonomy but with individualised and modified scoring. Similarly, it is natural that the criteria are not perfect and thus some reviewers might argue the validity and reliability of the proposed scoring system.

\section{LIMITATIONS AND STRENGTH OF THE CRITERIA SUGGESTED FOR PEER REVIEWING}

It was not possible to eliminate potential overlap among some of the items of the criteria. New reviewers may find it difficult to delineate between different items, thus opinion of additional reviewer(s) would be desirable to the editorial board to appropriately score the manuscript quality. Nevertheless, going through the relevant literature would give the reviewers confidence in dissecting out the merits and flaws present in the article they are reviewing. An emphasis has been given to English language because most of the articles submitted to the JNMA and many other journals of Nepal are/would be coming from authors who learn English as second or third language. Since this author believes that the criteria suggested in this article are not absolute, a discussion and consensus among the editorial board members, reviewers, authors, and the readers may be necessary to make the criteria more objective and acceptable for immediate use. Nevertheless, adhering to certain criteria is the only and right path towards better peer reviewing and one of the major ways of uplifting the standard of the national biomedical publications including that of JNMA.

In summary, peer review is a process of assessing the quality of manuscript submitted to a journal. This is a standard worldwide practice in biomedical publications. The journals with proper peer review are considered "standard". A set of criteria has been proposed to make peer reviewers, editors, contributors, and readers more conscious, honest, and responsible while reporting, reviewing, or processing a manuscript. In turn, the quality of publications would move towards internationalisation, national biomedical science - towards enrichment and national health care - towards better quality. Thus, let us keep in mind the saying by John Gardner while reviewing the manuscript submissions, "Liberty and duty, freedom and responsibility: that's the deal."

\section{REFERENCES}

1 I nternati onal Connittee of Ned cal J arnal Ed tors. Uhi form requi renents for manuscri pts subnintted to bi oned cal j arral $s$. BM 1991; 302: 338- 41.

2 Uni formrequi renents for manscri pts subnitted to bi oned cal j arral s: wi ting and ed ting for bi oned cal puld i cation, http. / / uvw i cnie. org/ \#aboutur, updated Nbv 2003, accessed in Nay 18, 2004.

3 Benos L, K rk K, Hall JE A personal vi ew howto revi ewa paper. Advan Physi d Edu 2003: 27: 47- 52.

4 Rerrie $D$ and $F$ anagin A Congress on bi oned cal peer revi ew history, ethics, and plans for the future (Ed tori al ). JAMA 1998; 280( 3) : 213.

5 Renni e D. Peer revi ew in Prague (Edi tori al). J AMA 1998a; 280( 3) : 214- 15.

6 Msaki an LA and Bero LA Publ i cati on bi as and research on passi ve snoki ng: conpari son of publ i shed and unpubl i shed stud es. J AMA 1998; 280(3) : 250-3.

7. Cal I ahamM, Wears RL, Weber EJ, Bart on C, Young G Posi ti ve autcone bi as and other li nitati ons in the outcone of research abstracts subnitted to a sci enti fi c neeti ing. JAMA 1998; 280( 3) : 254- 7.

8 Dckersin K Fredhan L, Fl egal KM Scott JD Crawey MM Is there a sex bi as in choosi ng ed tors? Epi derind ogy j arnal as an exanpl e. J AMA 1998; 280( 3) : 260-4.

9 Li nk AM US and non US subnissi ons: An anal ysi s of revi ever bi as. J AMA 1998; 280(3) : 246- 7.

10. J oyce J, Rabe Hesketh S. Vessel y S. Revi ewing the revi evs. The exampl e of chroni c fati gue syndrone. J AMA 1998; 280( 3) : 264-6.

11 Lee KP, Schotl and M Bacchetti P, Bero LA Associ ati on of J ournal Qual i ty I nd cators With Nethodbl ogi cal Qua i ty of Ginical Pesearch Artides. Fourth Internati ond Congress on Peer Revi ew i n Bi onedi cal Publ i cati on. http: // www anaassn. org/ publ i c/ peer/prc_program2001. ht m\#qual i ty, accessed on J un 1, 2004.

12. Weber EJ, Cal I ahamM, Włars RL, Bart on C, Young G Unpuld i shed research froma ned cal speci al i ty neeti ng: why i nesti gators fail to puld ish. J AMA 1998; 280:257-9.

13. Pi tki n RMand Branagan MA Can the accuracy of abstracts be i mproved by provi di ng speci fi c i nstructi ons? J AMA 1998; 280( 3) : 267-9.

14. Scherer RVand Cravey $B$ Peporting randonised d i ri cal tri als descriptors and use of structured abstracts. J AMA 1998; 280( 3) : 269- 72. 
15. O arke Mand Chal ners I. D scussi on secti on in reports of cortrd l ed tri als pud i shed in generd ned ca j arnal s. I sl ands in search of conti nents? J ANA 1998; 280(3) : 280-2.

16. Cho MK, J ustice AC, Wrker MA Berl in J A Weckerl e JF, Cal I ahamM, Rerni e D and the peer i nvesti gators. Maski ng author i darti ty in per revi ew What factors infl uence naski ng success? J ANA 1998; 280( 3) : 243-5.

17. Pooyen $S V$, Cod ee F, Evans S, Snith R B ack N Effect of bl i ndi ng and unnasking on the qual i ty of peer revi ew $A$ randonised tri al. J ANA 1998; 280(3) : 237-40.

18. $\operatorname{cod} e F$, Gal e $R$ Martin $\mathbb{N}$ Effect on the qual ity of peer revi ew of bl i nd ng revi evers and asking themto si gn thei $r$ reports. J AMA 1998; 280(3): 240-2.

19. Jautice $A C$, Cho $M$ W/rker MA Berlin J A Perrie $D$ and the peer i nvesti gators. Does naski ng author i danti ty i narove peer revi ew qual i ty? A randonnsed control l ed tri al. J AMA 1998a; 280( 3) : 240- 2.

20. J autice $A C$, Cho MK, W/rker MA Berl in JA Renni e D, and the per investi gators. Nasking athor identi ty in per revi eN What fact ors inf I uence masking success? J AMA 1998b; 280( 3) : 240-2.

21. Call I ahamM, Knopp RK, Gall agher E. Effect of Witten Feedback by Ed tors on Qall ity of Revi ens: Tho Randonised Trial s. Fourth Internati onal Congress on Peer Revi ew in Bi oned cal Publ i cati on. http: / / wrw ana-assn org/ publ ic/ peer/prc_programz001. htntqual ity, accessed on J un 1, 2004.

22. Marusic A Luki C IK Marusic M, Mananee D, Sharp D Horton R Peer Revi ewi in Snal I and Big NÆi cal J arnal s. http:// www. a ma-assn. org/publi c/peer / prc_progran2001. htmtsnal I, accessed on J u y 17, 2004.
23. Berkwits Mand Davi dof $f \mathrm{~F}$. Peer Revi ever Coi ni ons About Manuscri ipt-Speci fi c Acknow edgnent. Fourth I iternati onal Congress on Peer Revi ewi n B oned cal Publ i cation http.// www. a ma-assn. or g/ publi c/peer/ prc_progran2001. ht ntual ity, accessed on J un 1, 2004.

24. Abby M Massey MD, Gal and $\mathrm{uk} S$, Pol k HCJr. Peer revi ewi s an effecti ve screeni ng process to eval uate nædi cal manuscri pts. J AMA 1994; 272: 105 - 107.

25. Vaing $Q$ and Zhang B. Research desi gn and stati sti cal in Chi nese ned cal j ournal s. J AMA 1998; 280(3) : 283-5.

26. Bacchetti P. Peer reviewof statistics in ned cal research the other problem BM 2002; 324: 1271-3.

27. B ack N Pooyen SV, God $€ F$, Snith R Evans S. What nakes a good revi ever and a good revi ew for a general ned cal gener al ? J AMA 1998; 280( 3) : 231-3.

28. Perni e $D$ Freedomand responsi bi l i ty in ned cal publ i cati on Setti ng the bal ance ri ght. J AMA 1998b; 280 (3) : 300-302.

29. Horton $R$ The jarnd onbuodsperson A step toward sci enti fic press oversi ght. J AMA 1998; 280(3) : 217-8.

30. Hen VP, Vall voort HC, Cberbeke A PM Vhat are the factors deternini ing authorshi $p$ and the order of the authors' nanes? A study anong authors of the Nederl ands Tij dschrift voor Geneskunde (Dut ch J ournal of Medi ci ne). J AMA 1998; 280( 3) : 217- 8.

31. Paudl BH Nati onal heal th, Nepal Ned cal Associati on, and research ti ne to introspect. Proceeding of the $X X$ AI Nepal Nedi cal Conference (saveri $r$ ), Dharan Mar 5-8, 2003, pp. 51-4.

32. F etchner RH Fetchner SW Vagner 버 Ci i i cal Epi derind ogy: The esserti al s. VMl I i ans \& WM ki ns, 1996.

$$
\text { Les }
$$

